\title{
EXPANDED CROSS-DISCIPLINE IMPLEMENTATION STRATEGY OF DISCOVERY: A BIOMEDICAL ENGINEERING-THEMED EDUCATION PROGRAM BRIDGING SECONDARY AND POST-SECONDARY LEARNING
}

\author{
Locke Davenport Huyer ${ }^{l}$, Neal I. Callaghan ${ }^{l}$, Jose L. Cadavid Cardenas ${ }^{1 *}$, Huntley Chang ${ }^{1 *}$, Ileana Co ${ }^{l *}$, \\ Nicolas Ivanov ${ }^{l *}$, Jonathan Rubianto ${ }^{1 *}$, Nhien Tran-Nguyen ${ }^{l *}$ and Dawn M. Kilkenny ${ }^{1,2}$ \\ ${ }^{1}$ Institute of Biomaterials \& Biomedical Engineering, University of Toronto \\ ${ }^{2}$ Institute of Studies in Transdisciplinary Engineering Education \& Practice, University of Toronto \\ *These authors contributed equally to this work. \\ dawn.kilkenny@utoronto.ca
}

\begin{abstract}
High school science, technology, engineering, and math (STEM) curricula are generally knowledge-based in methodology and focus on content delivery in preparation for post-secondary study. However, the rapid technological change at the cutting edge and the rate of global integration in STEM highlight the importance in developing a holistic critical thinking framework for student learning. In 2016, graduate students at the Institute of Biomaterials \& Biomedical Engineering created Discovery, a collaborative high school educational program focused on critical thinking skill development through inquiry in the context of biomedical engineering (BME) [1]. Aligning with demonstrated evidence that inquiry-based active learning approaches are more effective in enhancing student learning than traditional teaching methods [2], evaluation in Discovery reinforces the value of a differential learning environment for high school STEM students who struggle in a knowledgefocused classroom [3,4]. In addition, the Discovery model is shown to enhance student attitudes towards STEM and post-secondary education, meanwhile providing robust opportunity for graduate trainees to develop and apply pedagogical skills through development of curriculum appropriate for university-preparatory students. Program impact provides opportunities to discuss this unique learning framework, collaborative delivery strategy, and implementation strategy of Discovery as a resource for translation to disciplines beyond BME, and institutions beyond the University of Toronto.
\end{abstract}

Keywords: STEM curriculum, graduate student teaching, pedagogical development, integrated curriculum, postsecondary learning, multi-level learning, biomedical engineering

\section{INTRODUCTION}

The changing landscape of academia requires graduate students to be proficient in the development of professional skills outside of the research environment [5], including capacity for knowledge translation of research outcomes to a non-expert audience, curriculum development and teaching, and effective project management [6]. In successfully preparing future faculty to assume academic roles and responsibilities, post-secondary institutions have shifted greater focus to providing teaching development programs for graduate trainee professional development [7]. University of Toronto (UofT) graduate students in the Faculty of Applied Science and Engineering have robust opportunity to learn fundamental teaching and curriculum design through participation in short-term workshops, engagement as course Teaching Assistants (TAs), or through graduate courses (i.e., Prospective Professors in Training (PPIT) program affiliated with APS1203 Teaching Engineering in Higher Education). While workshops provide insight to required fundamentals, application is limited. Additionally, not all TA positions allow trainee to develop teaching self-efficacy given that the required tasks may be focused on assessment or delivery of theory and/or experiences pre-determined by the course instructor. Courses such as PPIT bring significant depth and immersion to the learning experience; however, translation to practice is also limited. One mechanism to implement a cross-disciplinary approach is to develop a new course that allows translation of pedagogical fundamentals into practical application.

The Discovery Educational Program was created in 2016 by graduate trainees in Biomedical Engineering. This initiative arose given graduate student interests in community outreach, capacity to translate cutting-edge BME methodology and theory, and capacity to enhance societal comprehension and interest in STEM [1]. 
Consequently, participant interest has evolved to include graduate students interested in developing pedagogical skills and practice as well as high school teachers with significant interest in guiding their STEM students in achieving required global competencies. Given the high degree of personnel involvement and the identified impact on student outcomes, this paper seeks to discuss the mechanisms for translating this unique educational platform beyond BME to include the insight and involvement of graduate trainees across the various engineering disciplines at our institution and beyond.

Discovery provides opportunity for graduate students to teach their own curriculum that is designed and developed for senior high school STEM students in Grades 11 and 12 preparing to transition to post-secondary study. Considering the required themes of study in the Ontario senior high school STEM curriculum [8], we recognize the diversity of topics that could be created and incorporated into this learning structure by graduate students with expertise in Engineering units additional to BME (e.g., Physics curriculum delivered by students from the UofT Institute of Aerospace Studies (UTIAS)). Crossdisciplinary expansion of the Discovery program will strengthen curriculum diversity, expanding opportunities for high school students to examine global research topics through unique curricular foci and hands-on learning. This will be achieved through a growing network of high school class/teacher partners.

Although we originally considered an official partnership of Discovery with the local school board, we recognize the logistical challenges that might be required in accommodating a significant number of school partners. Therefore, it remains most effective to focus on the size and diversity of our graduate instructor cohort to discern the number of classrooms that can be supported in a given semester. To achieve effective pedagogical approaches during program expansion, we are ultimately pursuing program integration with existing graduate curriculum. Such integration will provide access to not only a diverse array of graduate students and their expertise, but also an array of teaching stream faculty with a vested interest in studying and improving pedagogical outcomes within the Faculty. Cross-disciplinary expansion of Discovery will allow students from across the UofT Faculty of Applied Science \& Engineering (FASE) to participate meaningfully with appropriate and ongoing feedback for continued selfimprovement in teaching. Given that we do not currently provide significant opportunities for our graduate students to learn how to be effective at teaching in higher education, Discovery expansion provides immense opportunity and multiple positive outcomes; we expect immediate impact with improved efforts of our TAs, as well as downstream effects as we develop the next generation of post-secondary faculty.

\section{PROGRAM FRAMEWORK}

\subsection{Activity Throughout the Semester}

Discovery is a STEM teaching and learning
collaboration between post-secondary trainees (undergraduate, graduate, postdoctoral), high school teachers, high school students, and university teaching stream faculty. Each semester, approximately 25 postsecondary student instructors work within UofT FASE practical teaching environments to guide critical thinking and problem-solving of high school students in the context of semester-long capstone-style projects $[3,4]$. These experiences are designed by graduate student instructors working collaboratively with high school teachers, and represent $10-15 \%$ of the final grade for each course (teacher-dependent). Curriculum is developed in advance of program launch for high school students and branches into the specific disciplines of the participating high school classes, including Biology, Chemistry and Physics. Project engagement requires high school students to visit oncampus facilities four times over the course of the semester. The first visit facilitates learning of relevant background theory and information as well as laboratoryspecific safety training; the second and third visits allow high school students to immerse in experimental learning within relevant facilities. Final student outcomes are shared at an on-campus end-of-semester scientific research symposium (student poster presentations). This final dissemination is complemented by a faculty keynote speaker whose research aligns with the global research theme for the semester (new themes are created each semester of programming). To date, 526 senior science students enrolled in university-preparatory (Grade 11 \& 12) Biology, Chemistry and Physics and 11 STEM teachers have been impacted by this unique teaching and learning experience $[3,4]$.

\subsection{Curriculum Development}

Each semester, a new central research theme of societal impact and of interest to students and graduate instructors is determined by the Discovery program executive (graduate student who assume the role of curriculum leaders) and high school teachers. Depending upon research interests and thesis expertise, graduate student instructors align with the most relevant high school discipline and generate discipline-specific research questions reinforcing accredited provincial senior science curriculum goals, as shown in Table 1 [8]. Specific curriculum is designed and developed by graduate students with feedback from the Discovery Programming Director and relevant high school teacher(s). Assessment of Discovery deliverables, including an essay on research topic motivation, project proposal, progress report, and final research poster, is completed by the high school teachers. 
Table 1: Representative discipline-specific research questions related to the central research theme of "Biomedical engineering technologies in assessment and treatment of chronic conditions".

\begin{tabular}{|l|c|}
\hline \multicolumn{1}{|c|}{ Discipline } & Research Question \\
\hline Biology & $\begin{array}{c}\text { How will you validate an assay for T-cell } \\
\text { migration using different drugs? }\end{array}$ \\
\hline Chemistry & $\begin{array}{c}\text { How will you optimize extended drug } \\
\text { release hydrogel formulation using } \\
\text { alginate capsules and coloured dye? }\end{array}$ \\
\hline Physics & $\begin{array}{c}\text { How will you design a low-cost } \\
\text { anemometer for assessment of breathing } \\
\text { rate in asthma patients? }\end{array}$ \\
\hline
\end{tabular}

\subsection{High School Partner Logistics}

The Discovery platform supports partnership between graduate students with a vested interested in developing skills in pedagogy and dynamic STEM teachers from local high schools. Curriculum development is conducted in strong collaboration, wherein graduate students contribute scientific research expertise that teachers match with expertise in teaching at the university-preparatory level. Once curriculum is developed, graduate student instructors are responsible to teach and guide student groups throughout the semester. Participating high school students attend campus as a regular class cohort accompanied by their teacher. Discovery currently works with two partner high schools that offer classes in all STEM disciplines relevant to the field of BME (Biology, Chemistry, and Physics). Because this constitutes immersive learning for approximately 165 high school students per semester, each school has independent, designated dates for on-campus learning to accommodate teaching facility capacity limits. However, all participating students and teachers are brought together at the end of the semester for the final research symposium.

\section{STRATEGIES FOR PLATFORM EXPANSION}

\subsection{Cross-Disciplinary Implementation}

Given our successes with BME-focused curriculum development and delivery, we have received interest from an increasing number of graduate students in other FASE departments, as well as STEM teachers from other high schools, for opportunities to participate in the Discovery learning platform. Our short-term goal is to engage students from all graduate units at the UofT ASE. However, in providing opportunity for practical translation of pedagogical skills for the intended increase of participating graduate students, we estimate required partnership with STEM teachers from a minimum of 8-10 local schools, as shown in Fig. 1.

Currently, all graduate student participation is voluntary. Depending upon the level of commitment, these students engage for varied amounts of time each semester. For example, graduate student lead instructors invest approximately 40 hours/semester working with high school teachers to develop curriculum that they consequently teach to other participating graduate students. This latter group, who act as program student mentors, invest approximately 20 hours of time each semester in working directly with high school student groups within the teaching facilities. All graduate students are eligible for recognition of their involvement through the School of Graduate Studies Graduate Professional Skills Program.

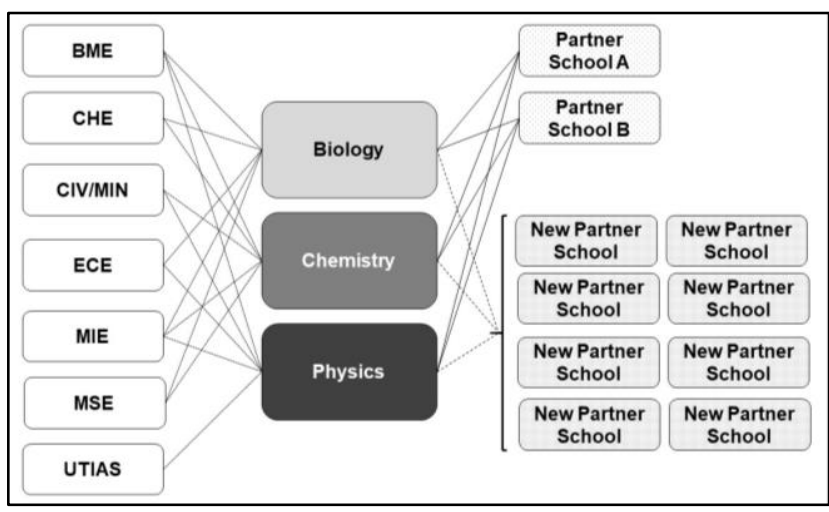

Fig. 1. Discipline-specific Faculty-wide partnership with local secondary school STEM departments.

\subsection{Partnership with ISTEP}

Apart from self-interest in developing pedagogical skills, graduate students volunteer their time to engage with their community through the Discovery program. Anonymous feedback over multiple program deliveries has demonstrated that these students find great value in the experience and would support inclusion as part of their official training. Consequently, we have examined opportunities to partner with the Institute for Studies in Transdisciplinary Engineering Education \& Practice (ISTEP), a unit within UofT FASE dedicated to enhancing the way we train our engineers to be leaders through focus on engineering education, professional competencies, and engineering practice. In the short-term, participation in Discovery allows graduate students to practically translate theory and methods learned in currently-existing courses offered by ISTEP. Long-term, we anticipate development of a unique standalone practical course for translation of pedagogical methods that complement the currentlyexisting graduate curriculum. Additionally, integration with a resource such as ISTEP allows graduate students to have interaction with a greater number of teaching stream and/or other teaching faculty with a vested interest to immerse in the program for their own professional development. Collectively, Discovery provides a framework involving a teaching and learning community that unites secondary and post-secondary educators. 


\subsection{Curriculum Expansion}

Although BME is a diverse field allowing different STEM disciplines to investigate similar topics using different theoretical approaches and strategies, program curriculum can be significantly enriched through participation of graduate students from other engineering fields who bring expertise outside the healthcare and medical sector (Table 2).

Table 2: Representative global themes aligning with Engineering graduate research.

\begin{tabular}{|c|c|}
\hline $\begin{array}{c}\text { Engineering } \\
\text { Unit }\end{array}$ & Sample Global Research Themes \\
\hline $\begin{array}{l}\text { Biomedical } \\
\text { Engineering }\end{array}$ & $\begin{array}{ll}\text { - } & \text { Cancer treatments } \\
\text { - } & \text { Prosthetics }\end{array}$ \\
\hline $\begin{array}{l}\text { Chemical } \\
\text { Engineering }\end{array}$ & $\begin{array}{ll} & \text { Climate } \\
\text { - } & \text { Cancer treatments }\end{array}$ \\
\hline $\begin{array}{l}\text { Electrical \& } \\
\text { Computer } \\
\text { Engineering }\end{array}$ & $\begin{array}{l}\text { - } \quad \text { Artificial Intelligence } \\
\text { - } \quad \text { Prosthetics }\end{array}$ \\
\hline
\end{tabular}

It remains that overlapping themes may arise between units; however, it is not imperative for all students to investigate the same global theme in order to facilitate practical learning and skill development. Furthermore, not every unit will have capacity to generate themes/research questions applicable to the ministry-mandated curriculum topics of high school STEM classes, which may result in engagement of only one or two disciplines (i.e., Biology and/or Physics) for some school partners (Table 3).

Table 3: Representative high school curriculum themes aligning with strengths of Engineering graduate units.

\begin{tabular}{|c|c|c|}
\hline FASE Unit & $\begin{array}{c}\text { STEM } \\
\text { Discipline(s) }\end{array}$ & $\begin{array}{c}\text { Representative } \\
\text { Ministry of Education } \\
\text { Themes }\end{array}$ \\
\hline $\begin{array}{l}\text { Biomedical } \\
\text { Engineering }\end{array}$ & $\begin{array}{l}\text { - Biology } \\
\text { - Chemistry } \\
\text { - Physics }\end{array}$ & $\begin{array}{ll}\text { - } & \text { Cellular biology } \\
\text { - } & \text { Microbiology } \\
\text { - } & \text { Biochemistry } \\
\text { - } & \text { Metabolic } \\
& \text { processes } \\
\text { - } & \text { Homeostasis } \\
\end{array}$ \\
\hline $\begin{array}{l}\text { Chemical } \\
\text { Engineering }\end{array}$ & $\begin{array}{l}\text { - Biology } \\
\text { - Chemistry }\end{array}$ & $\begin{array}{ll}\text { - } & \text { Cellular biology } \\
\text { - } & \text { Plants in the } \\
& \text { natural } \\
\text { environment } \\
\text { - } \text { Matter } \\
\text { - } \text { Reactions } \\
\text { - } \text { Quantities in } \\
\text { chemical reactions }\end{array}$ \\
\hline $\begin{array}{l}\text { Electrical \& } \\
\text { Computer } \\
\text { Engineering }\end{array}$ & $\begin{array}{l}\text { - Biology } \\
\text { - Physics }\end{array}$ & 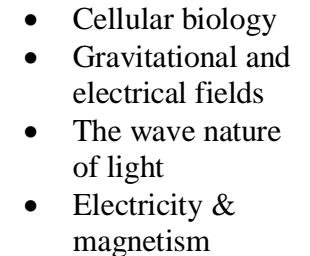 \\
\hline
\end{tabular}

\subsection{Program Sustainability}

Discovery promotes strong opportunity for graduate trainees to collaborate with high school teachers and build skillsets supported by continued feedback from this group of educators extensively trained in teaching and education at the university-preparatory level. Concomitantly, faculty members provide feedback on teaching methods in higher education. Collectively, there is great opportunity to develop a unique community of support in teaching and learning that benefits all stakeholders. While inclusion in official graduate curriculum will provide some stability for the Discovery program, a long-term goal is to immerse this learning framework within other faculties within the university, as well as other learning institutions. Therefore, logistical and learning resources will be required and continued support will be sought through relevant funding mechanisms internal and external to UofT FASE.

\section{RESULTS \& DISCUSSION}

\subsection{Partnership with Other Engineering Units}

Given capacity limitations of on-campus learning facilities, we have garnered support of other units within our Faculty for access to their teaching spaces. In particular, the Department of Chemical Engineering \& Applied Chemistry has approved access to their undergraduate teaching laboratory exclusive of the undergraduate schedule. This logistical support allows our graduate instructors and mentors to engage their designated Chemistry classes within the learning space best aligned to their curriculum and overall experience. Moving forward, we have established the support of the Department of Electrical \& Computer Engineering to allow student access to their relevant undergraduate learning spaces. This will allow graduate students to work in comfort in relevant learning spaces, meanwhile allowing high school students opportunity to broaden their perceptions of STEM workplaces and university learning.

\subsection{Partnership with ISTEP}

We have engaged in conversation with leaders and faculty within ISTEP regarding program inclusion in existing graduate curriculum. Graduate students currently enrol in APS1203 Teaching Engineering in Higher Education, a course designed to introduce students to curriculum, teaching, and learning within the context of engineering education. In combination with professional development seminars and requirement for creation of a teaching dossier, APS1203 also represents the Prospective Professors in Training (PPIT) Program. This program was designed to prepare doctoral students for the rigours of a career in academia. Co-ordinators are currently developing the requirement for a practical component within this course; participation in Discovery has been identified as a relevant experience to meet this course requirement by the 
co-ordinators. Given outcomes of this pilot integration, a long-term goal is to create a new course in practical teaching built around a community of learning with high school teacher partners.

\subsection{Broadening Curriculum Content}

As shown in Table 3, participation of graduate students from across the Faculty of Engineering \& Applied Science will significantly broaden the curriculum that can be developed within the program framework. Additionally, different graduate instructors will have capacity to personalize their teaching to the classroom/school with which they are aligned, making for a more invigorating and engaging experience. Recognizing that graduate students are partnered with high school teachers and classes aligning with their thesis research expertise and interest results in a very personalized experience for the instructors and also the high school student participants.

\subsection{Online Learning}

Given the current unpredictable nature of on-campus engagement, combined with distance learning at all levels of education, we anticipate that the Discovery platform can be sustained through virtual interactions and discussions. The framework is currently being executed using an online approach that allows graduate student instructors continued opportunity to develop and teach curriculum. The modified curriculum includes online laboratory simulations in place of practical, hands-on learning components, and high school students are implementing learned knowledge of lab outcomes by analyzing datasets generated by their graduate instructors. Virtual meetings throughout the term will allow continued interactive engagement between graduate student instructors and high school participants. This curricular adaptation, currently piloted with one school partner, will incorporate virtual 3D simulations that are currently available free-of-charge for high school student use as a consequence of COVID-19 impact to the learning environment. Although less desirable than face-to-face teaching \& learning through stakeholder immersion within university teaching environments, this pilot allows our graduate student instructors the opportunity to adapt to teaching and learning in the online environment and discern methods for optimal integration into the existing framework.

Pending success of current piloting of this strategy, we anticipate opportunities to develop a hybrid model of teaching and learning that allows graduate students to interact virtually with high school students, teachers, and teaching stream faculty while developing and delivering their relevant curriculum. Teachers and faculty will retain capacity to mentor and advise graduate student instructors through observations of online teaching and learning sessions, and use virtual communication to provide feedback. Furthermore, there is opportunity for program expansion to schools elsewhere in Ontario and Canada through incorporation of online instruction and distance learning into the existing framework. This adaption will allow for maintenance of the program philosophy to promote interactive learning through "personalized" curriculum development and delivery.

\section{CONCLUSIONS}

Given the changing academic landscape, the needs of our graduate students are evolving to be competitive postgraduation, whether they choose careers in academia or otherwise. We have found success in multiple levels of learning through the Discovery Educational Program. Not only does this platform provide opportunities for our graduate students to translate their learned theory and methods in practical pedagogy, but we have identified profound impact on the learning of the universitypreparatory STEM student participants. To date, this program has focused on themes in Biomedical Engineering, a diverse field of engineering that allows curriculum development in the areas of high school Biology, Chemistry, and Physics. Given increased interest in this educational model, we see great opportunity for cross-disciplinary expansion by initially engaging graduate students from other departments within the Faculty of Engineering \& Applied Science, and beyond. Pending logistical capability to work with an increased number of high school partners, we envision capacity to expand the platform beyond Engineering to include complementary disciplines in the Arts \& Sciences. There is also intriguing capacity to incorporate online elements to enhance the teaching and learning experience of both our graduate instructors and the high school students.

\section{Acknowledgements}

The authors acknowledge the IBBME and NSERC PromoScience Program (PROSC 515876-2017) for financially supporting this educational program. Toronto District School Board STEM teacher partners (E. Scherer, S. Dicks, T. Frost) and administrators (A. Vandyke \& S. Micelli) have been invaluable and fundamental to program development and expansion.

\section{References}

[1] Locke Davenport Huyer, Genevieve Conant, Cindy V. Bui, Ben G. Kinsella, Andrea Vegh, Sherif Ramadan, Brittany Lauton, Andrey I. Shukalyuk and Dawn M. Kilkenny, "Discovery program: integrating biomedical engineering graduate instructors with high school STEM curriculum," in Proc. CEEA Canadian Engineering Education Conf., CEEA17, Andy Fisher (ed.) (Toronto, ON; 4-7June 2017), 7 pp., 2017.

[2] Joel A. Michael, Mary Pat Wenderoth, Harold I. Modell, William Cliff, Barbara Horwitz, Philip 
McHale, Daniel Richardson, Dee Silverthorn, Stephen Williams, and Shirley Whitescarver. "Undergraduates' understanding of cardiovascular phenomena," $A d v$ Physiol Educ vol. 26, pp. 72-84, 2002.

[3] Locke Davenport Huyer, Genevieve Conant, Cindy V. Bui, Sherif Ramadan, Ben G. Kinsella, Andrea Vegh, Andrew Effat, Janice Wong, Neal Callaghan, Brittany Lauton, Andrey Shukalyuk, and Dawn M. Kilkenny, "Immersing biomedical engineering graduate instructors into high school STEM curriculum: the IBBME Discovery Program at the University of Toronto," BMES Annual Meeting (2017), Phoenix, AZ.

[4] Locke Davenport Huyer, Neal Callaghan, and Dawn M. Kilkenny, "Discovery: immersing biomedical engineering graduate instructors into high school STEM curriculum," BMES Annual Meeting (2018), Atlanta, GA.

[5] Christopher S. Hayter and Marla A. Parker. "Factors that influence the transition of university postdocs to non-academic scientific careers: An exploratory study." Research Policy 48.3 (2019): 556-570.

[6] Hugo Horta. (2020) PhD Students' Self-Perception of Skills Acquired During Their PhD and Plans for Their Postdoctoral Careers: A Joint Analysis of Doctoral Students at Three Flagship Universities in Asia. In: Sónia Cardoso, Orlanda Tavares, Cristina Sin, and Teresa Carvalho (eds) Structural and Institutional Transformations in Doctoral Education: Social, Political, and Student Expectations. Issues in Higher Education. Palgrave Macmillan, Cham, Switzerland.

[7] Susan Vajoczki, Nancy Fenton, Karen Menard, and Dawn Pollon (2011). Teaching-Stream Faculty in Ontario Universities. Toronto: Higher Education Quality Council of Ontario.

[8] Ontario Ministry of Education (2008). The Ontario Curriculum Grades 11-12: Science. 